\title{
Molecular Epidemiology of Multidrug-resistant Escherichia coli from Urinary Tract Infections
}

\author{
Divya Puthenkandathil Sukumaran, Mohamed Hatha \\ Department of Marine Biology, Microbiology and Biochemistry, School of Marine Sciences, Cochin University of Science \\ and Technology, Lakeside campus, Cochin 682 016, Kerala, India
}

\begin{abstract}
Objectives: The purpose of this study was to investigate the phylogenetic groups, antibiotic resistance, antibiotic resistance genes (ARGs), integrons, extraintestinal virulence genes and genetic diversity of Escherichia coli isolates from human urinary tract infection.

Methods: A total of $100 \mathrm{E}$. coli isolates were collected from patients with urinary tract infections in Kerala, South India. Antibiotic susceptibility testing of all $E$. coli isolates against different antibiotics was determined by the disc diffusion method. Phylogenetic groups, extraintestinal virulence genes, ARGs, and integrons were detected by PCR. Enterobacterial repetitive intergenic consensus polymerase chain reaction (ERIC-PCR) was used to check the genetic relatedness among $E$. coli isolates.

Results: $E$. coli isolates have mainly belonged to phylogenetic group B2. Resistance to ampicillin was most frequent among the $E$. coli isolates followed by resistance to cefoxitin, cefpodoxime, nalidixic acid, trimethoprim, and cotrimoxazole. Among E. coli isolates, 96\% were multidrug-resistant (MDR), and 86\% and 32\% harbored ARGs and integrase 1 (int 1) respectively. Seventy-nine percent of the isolates were extraintestinal pathogenic $E$. coli (ExPEC), and $86 \%$ of them $(n=68)$ harbored ARGs. One extensively drug-resistant ExPEC was obtained in this study. The present study revealed a significant association between the presence of virulence genes and antibiotic resistance. A high degree of genetic diversity was observed among the ARGs-harboring $E$. coli isolates.
\end{abstract}

Conclusion: Understanding the association between extraintestinal virulence genes and antibiotic resistance genes would result in the proper treatment of urinary tract infections. J Microbiol Infect Dis 2021; 11(2):66-73.

Keywords: Escherichia coli; antibiotic resistance; ExPEC; India

\section{INTRODUCTION}

Antibiotic-resistant bacteria have caused a major public health concern all over the world. The extensive use of antibiotics in hospital settings, particularly when the infection control practices are inadequate, has contributed to an increased prevalence of antibiotic-resistant bacteria. The antibiotics commonly used to treat bacterial infections are cephalosporins, trimethoprim, and quinolones. However, antibiotic resistance is a major problem hindering the treatment of bacterial infections. According to the World Health Organization [1], $3^{\text {rd }}, 4^{\text {th }}$, and $5^{\text {th }}$ generation cephalosporins and quinolones are categorized as critically important with the highest priority, and $2^{\text {nd }}, 3^{\text {rd }}$ generation cephalosporins, and trimethoprim are listed as highly important antibiotics.

Escherichia coli is one of the major pathogens that cause common hospital and communityacquired infections across the world. E. coli strains could be broadly categorized as (1) commensal strains, (2) intestinal pathogenic strains (diarrheagenic E. coli), and (3) extraintestinal pathogenic $E$. coli (ExPEC). ExPEC associates with human and animal infections that occur outside of the intestinal tract, such as urinary tract and bloodstream

Correspondence: Dr. Divya Puthenkandathil Sukumaran, Department of Marine Biology, Microbiology and Biochemistry, Cochin University of Science and Technology, Cochin, Kerala, India 
infections. The ExPEC possesses a broad range of virulence genes such as adhesins, iron acquisition systems, polysaccharide coatings, and toxins associated with the extraintestinal disease. Uropathogenic E. coli (UPEC), sepsisassociated pathogenic E. coli (SePEC), newborn meningitis E. coli (NMEC), and avian pathogenic E. coli (APEC) are different pathotypes that belong to ExPEC which may cause various infectious diseases in humans and animals [2].

Urinary tract infections (UTIs) caused by multidrug-resistant (MDR) E. coli harboring antibiotic-resistant genes pose a serious challenge to clinicians because these bacteria are resistant to a broad range of antibiotics. These MDR $E$. coli have complicated the management of UTIs and limit treatment options. To curb the threat of antibiotic resistance pathogens, knowledge of antibiotic susceptibility, genes encoding resistance, and genetic relatedness are essential. Further, antibiotic resistance in $E$. coli is encoded on mobile genetic elements, thus enabling the rapid dissemination of antibiotic resistance genes among different species of bacteria. Therefore, molecular characterization of the MDR $E$. coli from human urinary tract infection is important in successful infection control, involving the better prediction of the antibiotics for treatment. Thus, the objectives of this study were to determine the phylogenetic groups, antibiotic resistance, antibiotic resistance genes (ARGs), integrons, extraintestinal virulence genes and genetic diversity of $E$. coli isolates from human urinary tract infection.

\section{METHODS}

\section{Collection and identification of $E$. coli}

Between January 2013 and June 2013, consecutive non-duplicate strains of $E$. coli $(\mathrm{n}=$ 100 ) of human urinary tract infection origin were collected from one hospital (Mar Augustine Jubilee hospital) and two diagnostic centers (Dianova Lab and Hi-Tech Lab, Cochin) in Cochin city, Kerala, South India. The study protocol was approved by the institutional ethics committee. E. coli isolates were characterized by biochemical analyses [3] and amplification of the uid $A$ gene [4]. E. coli DNA was isolated using the Proteinase-K digestion method [5].

\section{Phylogenetic analysis}

The phylogenetic group was determined for $E$. coli isolates $(n=100)$ by the new phylogenetic group assignment polymerase chain reaction (PCR)-based method [6]. Clermont et al. [6] classified $E$. coli into 7 groups such as A, B1, $B 2, C, D, E$, and $F$. PCR reactions were performed under the following conditions: denaturation $4 \mathrm{~min}$ at $94{ }^{\circ} \mathrm{C}, 30$ cycles of $5 \mathrm{~s}$ at $94{ }^{\circ} \mathrm{C}$ and $20 \mathrm{~s}$ at $57{ }^{\circ} \mathrm{C}$ (group E) or $59{ }^{\circ} \mathrm{C}$ (quadruplex and group $\mathrm{C}$ ), and a final extension step of 5 min at $72{ }^{\circ} \mathrm{C}$, on a ProFlex ${ }^{\mathrm{TM}} 3 \times 32$-Well PCR system (Applied Biosystems, United States).

\section{Detection of extraintestinal virulence factor genes}

The PCR detection of five key virulence genes was performed as described by Johnson and Stell [7]. Based on PCR results, E. coli isolates positive for two or more virulence genes (papAH, papC, sfa/focDE, iutA, and kpsMT II) were classified as ExPEC [7]. PCR conditions were used in the following way: 1 cycle of initial denaturation ( $94{ }^{0} \mathrm{C}$ for $5 \mathrm{~min}$ ), followed by 30 cycles of denaturation $\left(94{ }^{0} \mathrm{C}\right.$ for $\left.30 \mathrm{~s}\right)$, annealing $\left(64{ }^{\circ} \mathrm{C}, 30 \mathrm{~s}\right)$, extension $\left(68{ }^{\circ} \mathrm{C}, 3 \mathrm{~min}\right)$ and final extension $\left(72{ }^{0} \mathrm{C}, 10 \mathrm{~min}\right)$ on a ProFlex $^{\text {TM }} 3 \times 32-$ Well PCR system (Applied Biosystems, United States).

\section{Antibiotic susceptibility test}

Antibiotic susceptibility testing of all E. coli isolates against different antibiotics was determined by the disc diffusion method [8] on Mueller-Hinton agar (Hi-Media, India). The antibiotics and concentration used were as follows; ampicillin (Amp, $10 \mathrm{mcg}$ ), cefotaxime (Ctx, $30 \mathrm{mcg})$, cefoxitin (Cx, $30 \mathrm{mcg}$ ), cefpodoxime (Cpd, $10 \mathrm{mcg}$ ), ceftazidime (Caz, $30 \mathrm{mcg}$ ), ceftriaxone (Ctr, $30 \mathrm{mcg}$ ), cefuroxime (CMX, $30 \mathrm{mcg})$, chloramphenicol (C, $30 \mathrm{mcg})$, ciprofloxacin, (Cip, $30 \mathrm{mcg}$ ), co-trimoxazole (Co, $25 \mathrm{mcg}$ ), gentamicin (Gen, $10 \mathrm{mcg}$ ), nalidixic acid ( $\mathrm{Na}, 30 \mathrm{mcg})$, streptomycin (, $10 \mathrm{mcg}$ ), tetracycline (Te, $30 \mathrm{mcg}$ ) and trimethoprim (Tr, 5 $\mathrm{mcg}$ ). The results were interpreted according to the clinical laboratory standards institute guidelines [9]. MAR index or Multidrug resistance (MDR, resistance to 3 or more antibiotic classes) was calculated by dividing the number of antibiotics to which the isolate was resistant by the total number of antibiotics used [10]. 


\section{Detection of antibiotic resistance genes and integrase genes}

PCR was used for the detection of gene encoding resistance against clinically relevant antibiotics including bla $a_{T E M}$ [11], bla $a_{S H V}$ [12]

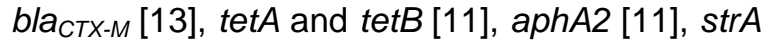
[14], sul1 and sul2 [11], catl [11] dhfr1, dhfr7 [15], and qnrA [16], qnrS [17], and aac(6')-Ib-cr [18]. The integrons were detected through PCR amplification of int1 [19], int2 and int3 integrase genes [20]. The PCR reactions were carried out using ProFlex ${ }^{\mathrm{TM}}$ 3×32-Well PCR system (Applied Biosystems, United States) under conditions as follows: initial denaturation at $94{ }^{\circ} \mathrm{C}$ for $5 \mathrm{~min}$, followed by 30 cycles of $94{ }^{\circ} \mathrm{C}$ for $30 \mathrm{~s}$, annealing $\left(50{ }^{\circ} \mathrm{C}\right.$ for bla $a_{T E M}, b l a_{S H V}$, tet $A$, tetB, aphA2, strA, sul1, sul2, qnrA, qnrS, aac(6')-lb-cr, int2, int3; $55{ }^{\circ} \mathrm{C}$ for dhfr 1 , dhfr7, int $1 ; 60{ }^{\circ} \mathrm{C}$ for bla CTX-M , catl) for $30 \mathrm{~s}$, and $72{ }^{\circ} \mathrm{C}$ for $1.5 \mathrm{~min}$, with a final extension at $72{ }^{\circ} \mathrm{C}, 5 \mathrm{~min}$.

\section{ERIC fingerprinting}

Enterobacterial repetitive intergenic consensus polymerase chain reaction (ERIC-PCR) was used to check the genetic relatedness among $E$. coli isolates [21]. The cycling conditions were as follows: 1 cycle of initial denaturation at $94{ }^{\circ} \mathrm{C}$ for 5 min, followed by 30 cycles of denaturation (94 $\left.{ }^{0} \mathrm{C}, 30 \mathrm{~s}\right)$, annealing $\left(60{ }^{\circ} \mathrm{C}, 1 \mathrm{~min}\right)$, extension $\left(72{ }^{\circ} \mathrm{C}, 1 \mathrm{~min}\right)$ and final extension $\left(72{ }^{\circ} \mathrm{C}, 5 \mathrm{~min}\right)$ on a ProFlex ${ }^{\mathrm{TM}} 3 \times 32-$ Well PCR system (Applied Biosystems, United States). ERIC-PCR fingerprints of the $E$. coli isolates were analyzed using Fingerprint data analysis Gelcompare II version 6.0 software (Applied Maths, Texas).

\section{Statistical analysis}

A Pearson's Chi-squared test was used (i) to test the distribution of $E$. coli in different phylogenetic groups, (ii) to compare the association of virulence genes (VGs) and resistance to antibiotics, (iii) to compare the association of VGs and ARGs, and (iv) to compare the association of ARGs and int 1 in $E$. coli isolates. Statistical analysis of the results was carried out using IBMSPSS version 22 (IBM Corporation, Armonk, New York, USA). Statistical significance was set at a $p$-value of $<0.05$.

\section{RESULTS}

\section{Phylogenetic groups}

Phylogenetic analysis of $E$. coli isolates recovered from UTIs, showed that such strains mainly belonged to phylogenetic group B2 $(61 \%)$, followed by $A(10 \%)$, Unknown $(9 \%), D$ (6\%), F (6\%), E (4\%), B1, C (2\%) (Figure 1). E. coli isolates were significantly more belonged to B2 than all other groups $(p<0.05)$. Phylogenetic group $A$ isolates were significantly more than group E, B1, and C isolates $(p<0.05)$.

\section{Prevalence of EXPEC}

EXPEC associated virulence genes were detected in 84 E. coli isolates. Seventy-nine percentages of $E$. coli isolates carried two or more extraintestinal virulence genes and termed as ExPEC. iutA, kpsMT II, and papC genes were detected in $67 \%, 63 \%, 57 \%$ of isolates respectively. $p a p A H$ and $s f a / f o c D E$ were detected in $15 \%$ and $14 \%$ of the isolates, respectively. The iutA and kpsMT II were the most frequent combination of virulence genes detected. Fifty-four percent of $E$. coli isolates showed this combination. Forty percent of $E$. coli isolates showed iut $A+$ pap $C$ combination.

\section{Antibiotic resistance}

In the present study, we found that out of $100 \mathrm{E}$. coli isolates, $96 \%$ were multidrug-resistant (resistant to 3 or more antibiotics). Among the various antibiotics, resistance to ampicillin $(98 \%)$ was most frequent among the $E$. coli isolates followed by resistance to cefoxitin (92\%), cefpodoxime $(82 \%)$, nalidixic acid $(78 \%)$, trimethoprim (63\%), and co-trimoxazole (56\%). $E$. coli isolates showed moderate resistance $(47 \%-38 \%)$ against ciprofloxacin (47\%), tetracycline $(46 \%)$, cefuroxime $(45 \%)$, cefotaxime (41\%), and streptomycin (38\%). Resistance to ceftazidime, ceftriaxone, gentamicin, and chloramphenicol, were lower, with percentages of $26 \%, 23 \%, 22 \%$ and $13 \%$, respectively (Suppl. Fig. 2). Seventy percentages of isolates showed resistance against more than 5 antibiotics. Multiple antibiotics resistance (MAR) index of individual isolates showed that $96 \%$ of the urinary isolates had MAR index $>0.2$ with the highest being 1 (Suppl. Table 2). Multidrug-resistant E. coli isolates have significantly more belonged to the B2 group than that of other groups $(p<0.05)$.

\section{Antibiotic resistance genes}


In our study 86 ARGs-harboring E. coli were detected. Seventy-seven percentages of ARGsharboring isolates possessed two or more genes conferring resistance to multiple antibiotic classes. Among ampicillin-resistant isolates $(\mathrm{n}=$ 98) $b / a_{T E M}$ and bla $a_{S H V}$ was detected in $71.4 \%$ and $38.7 \%$ of isolates respectively. bla was detected in $15.7 \%$ of cefotaxime resistant isolates. Sulphonamide resistance was mainly associated with the presence of the sul1 gene $(91 \%)$, followed by sul2 (69.6\%). Among tetracycline-resistant strains $(n=46)$, tetA $(91.3 \%)$ was the most frequently detected resistance determinant, than tetB. Regarding aminoglycosides, the strA (84.2\%) was widely present in streptomycin-resistant isolates, and aphA2, involved in the gentamicin resistance was detected in $81.8 \%$ of the isolates. cat 1 gene was detected in $84.6 \%$ of chloramphenicol resistant isolates. dhfr 1 and $d h f r 7$, involved in the trimethoprim resistance were detected in $19 \%$ and $7.9 \%$ of the isolates respectively. Among quinolone-resistant isolates, plasmidmediated quinolone resistance (PMQR) genes such as qnrA, qnrS, and aac(6')-lb-cr were detected in $15.3 \%, 28.2 \%$, and $12.8 \%$ respectively.

\section{Prevalence of integrase}

The percentage of int1- positive E. coli was $32 \%$. All the int1-positive $E$. coli isolates were multidrug-resistant. Apart from cat1 and qnrS genes, all the ARGs showed a statistically significant $(p<0.05)$ association with int1 among
E. coli isolates. Int 2 and int 3 were absent in all the isolates tested.

\section{Co-occurrence of virulence genes and antibiotic resistance genes}

Concerning antibiotic resistance, the results showed that $98.7 \%(78 / 79)$ of the ExPEC isolates were resistant to two or more antibiotics; and that $86.0 \%$ (68/79) were ARG-harboring ExPEC. There was a statistically significant association between the presence of the iutA gene and bla CTXXM $_{\text {, }}$ tet $B, \operatorname{str} A, \operatorname{dhfr} 7(\mathrm{p}>0.05)$. bla $a_{C T X-M}$ harboring isolates were showed a negative association with iutA gene. papC was not significantly $(p>0.05)$ associated with ARGs, except bla $a_{S H V}$ and qnrA. kpsMT II gene was associated with bla $a_{T E M}$ and bla $a_{S H V}$. papAH was significantly associated with bla $a_{T E M}, \quad b / a_{S H V}$, bla ${ }_{C T X-M}$, su1l, tetB, strA, cat1, dhfr1, dhfr7, and qnrA (Table 1). Integrase 1 (int1) was significantly more associated with $p a p A H$ and kpsMT II.

\section{ERIC fingerprints}

E. coli isolates harboring two or more ARGs were characterized by ERIC PCR to determine the genetic diversity and phylogenetic relationship among the strains. In ERIC PCR, all the isolates were typeable and produced amplicon sizes ranging from 150 to $1400 \mathrm{bp}$. ERIC fingerprint analysis showed that there was great genetic diversity among multi-drugresistant $E$. coli isolates, with 59 isolates divided into fourteen clusters (Figure 2).

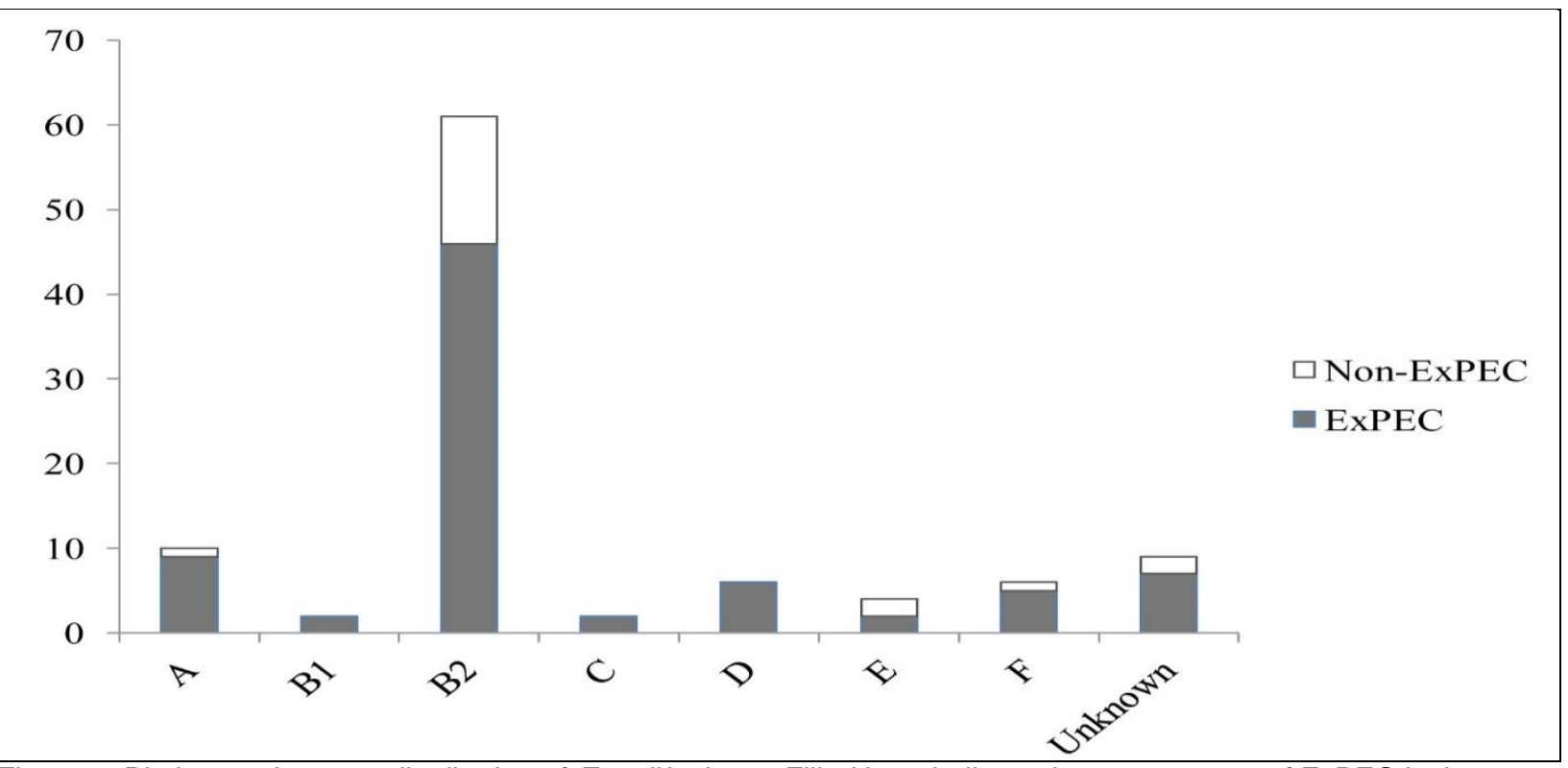

Figure 1. Phylogenetic group distribution of E. coli isolates. Filled bars indicate the percentages of ExPEC isolates. 


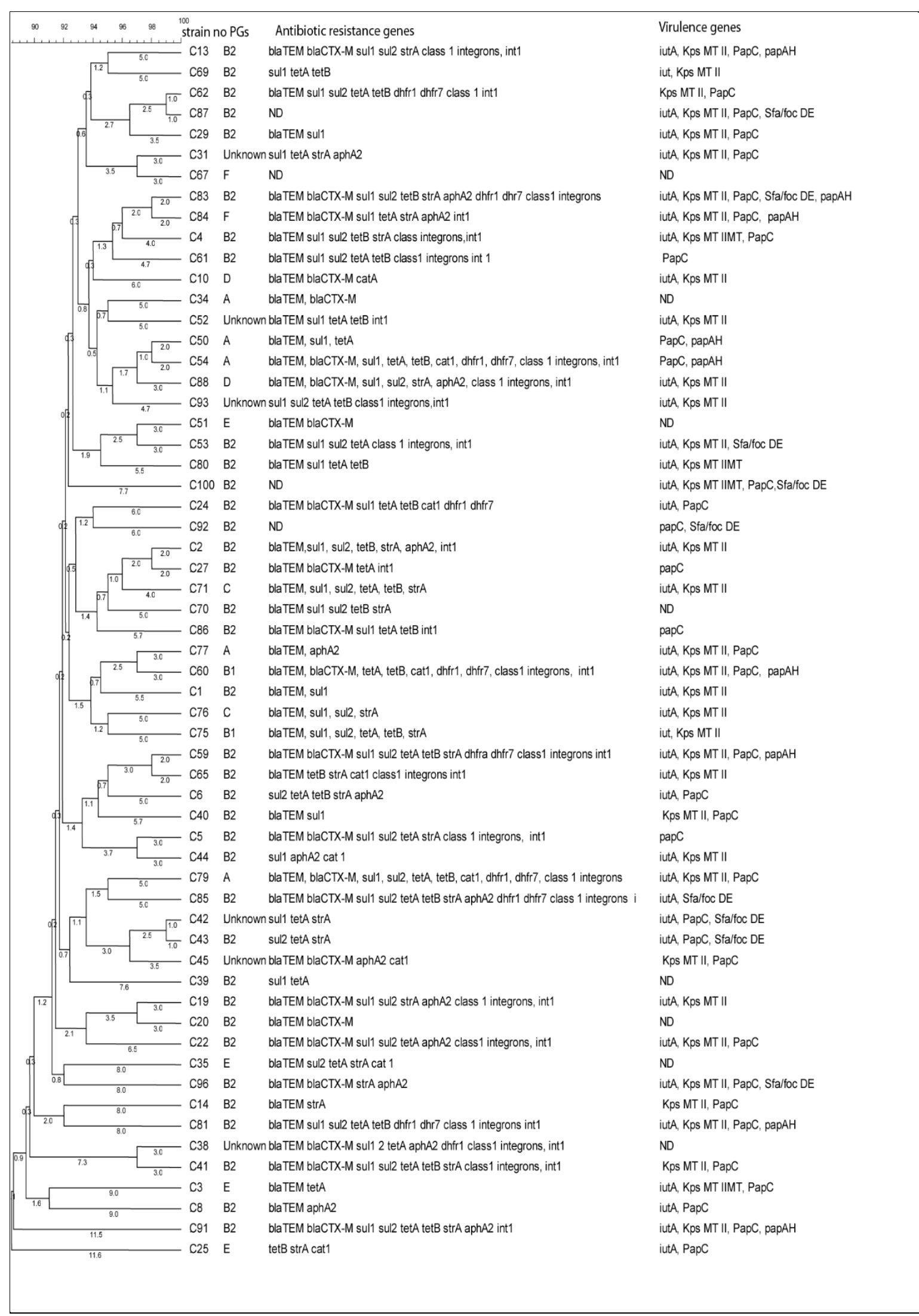

Figure 2. Genetic relatedness of ERIC-PCR profiles of antibiotic resistant E. coli isolates. PGs (Phylogenetic groups); ND: Not detected; A, B1, B2, C, D, and F denotes different phylogenetic groups of $E$. coli. 
Table 1. Prevalence of virulence genes in ARG-harboring and Non-ARG harboring E. coli isolates.

\begin{tabular}{|c|c|c|c|c|c|}
\hline ARG & iutA $(\mathrm{n}=67)$ & kpsMT II $(\mathrm{n}=63)$ & papC $(\mathrm{n}=57)$ & papAH $(\mathrm{n}=15)$ & sfa/focDE $(\mathrm{n}=14)$ \\
\hline bla TEM $(\mathrm{n}=70)$ & $67.1 \%(45)$ & $76.1 \%(48) *$ & $68.4 \%(39)$ & $93.3 \%(14)^{*}$ & $35.7 \%(5) *$ \\
\hline$b^{\prime} a_{S H V}(\mathrm{n}=38)$ & $40.3 \%(27)$ & $42.8 \%(27)^{*}$ & $43.8 \%(25)^{*}$ & $73.3 \%(11)^{*}$ & $21.4 \%(3) *$ \\
\hline$b^{b l a} a_{C T X M}(\mathrm{n}=26)$ & $20.8 \%(14) *$ & $23.8 \%(15)$ & $29.8 \%(17)$ & $46.6 \%(7) *$ & $21.4 \%(3)$ \\
\hline sul1 $(\mathrm{n}=51)$ & $55.2 \%(37)$ & $57.1 \%(36)$ & $45.6 \%(26)$ & $66.6 \%(10) *$ & $42.8 \%(6)$ \\
\hline sul2 $(\mathrm{n}=39)$ & $41.7 \%(28)$ & $39.6 \%(25)$ & $35.0 \%(20)$ & $46.6 \%(7)$ & $42.8 \%(6)$ \\
\hline $\operatorname{tet} A(n=42)$ & $43.2 \%(29)$ & $38.0 \%(24)$ & $43.8 \%(25)$ & $53.3 \%(8)$ & $42.8 \%(6)$ \\
\hline tetB $(\mathrm{n}=32)$ & $36.8 \%(24) *$ & $33.3 \%(21)$ & $31.5 \%(18)$ & $46.6 \%(7) *$ & $21.4 \%(3)^{*}$ \\
\hline $\operatorname{str} A(\mathrm{n}=32)$ & $40.2 \%(27) *$ & $31.7 \%(20)$ & $36.8 \%(21)$ & $46.6 \%(7) *$ & $35.7 \%(5)$ \\
\hline $\operatorname{aph} A 2(\mathrm{n}=28)$ & $20.8 \%(14)$ & $19.0 \%(12)$ & $19.2 \%(11)$ & $20 \%(3)$ & $21.4 \%(3)$ \\
\hline $\operatorname{cat1}(n=11)$ & $11.9 \%(8)$ & $11.1 \%(7)$ & $10.5 \%(6)$ & $20 \%(3)^{*}$ & $0 \%(0)^{*}$ \\
\hline$d h f r 1(n=12)$ & $13.4 \%(9)$ & $12.6 \%(8)$ & $14.0 \%(8)$ & $26.6 \%(4) *$ & $14.2 \%(2)$ \\
\hline$d h f r 7(\mathrm{n}=10)$ & $11.9 \%(8)$ & $11.1 \%(7)$ & $12.2 \%(7)$ & $20 \%(3)$ & $7.1 \%(1)$ \\
\hline qnrA $(\mathrm{n}=12)$ & $10.4 \%(7)$ & $12.6 \%(8)$ & $17.5 \%(10) *$ & $33.3 \%(5)^{*}$ & $14.2 \%(2)$ \\
\hline qnrS $(\mathrm{n}=22)$ & $25.3 \%(17)$ & $23.8 \%(15)$ & $19.2 \%(11)$ & $13.3 \%(2) *$ & $14.2 \%(2)$ \\
\hline $\operatorname{aac}\left(6^{\prime}\right)-\operatorname{lb}-c r(\mathrm{n}=10)$ & $10.4 \%(7)$ & $9.5 \%(6)$ & $12.2 \%(7)$ & $20 \%(3)^{*}$ & $0(0) *$ \\
\hline
\end{tabular}

Percentages in the parenthesis were calculated with the column values. *Significant, $p$ value; $(p<0.05)$.

\section{DISCUSSION}

Urinary tract infections (UTIs) are one of the most common infections worldwide and $E$. coli is the main causative agent. In the present study, 100 urinary $E$. coli isolates from human urinary tract infection were analyzed for their phylogenetic background, resistance to various antibiotics, presence of ARGs, and presence of virulence factors.

Interestingly, $61 \%$ of UTI isolates belonged to phylogenetic group B2, which is inconsistent with other studies [22]. More than seventy percentages of ExPEC isolates belonged to pathogenetic phylogenetic groups (B2, D, E, and $\mathrm{F})$ than non-pathogenetic groups. E. coli responsible for extra-intestinal infection were far more likely to be members of phylogenetic groups B2 or D than A or B1 [7].

Regarding the prevalence of ExPEC, we identified 79 ExPEC harboring 2 or more virulence genes. Our results show a higher frequency of iut $A$, kpsMTII, and papC compared with the rest of the genes, which may indicate a crucial role of these virulence genes in the pathogenesis. iutA, kpsMT II, and papC gene encode aerobactin receptor, group II capsular polysaccharide synthesis, and $P$ fimbrial assembly systems, respectively. Genes coding for fimbrial adhesive systems represent the most common factors for the virulence of $E$. coli in UTIs. papC and sfa genes encoding adhesins are known to be involved in binding to urinary tract epithelial cells [23]. 
Antibiotic resistance is becoming a major concern all over the world with reported rates of multidrug-resistant $E$. coli in the urinary tract. In our study, $94 \%$ of isolates were multidrugresistant. A high percentage of $E$. coli isolates exhibited resistance to $\beta$-lactam antibiotics, such as cefoxitin, cefpodoxime, cefuroxime, cefotaxime. This is a reason for concern because most of these antibiotics continue to be the first-line treatment option for UTIs. In the present study, $56 \%$ and $63 \%$ of $E$. coli isolates showed resistance against co-trimoxazole and trimethoprim, respectively. Trimethoprim is one of the main antibiotics used for treating patients with uncomplicated UTIs and normal kidney function. Quinolones are among the most common therapeutic agents used in treating UTIs. In this study, the prevalence of nalidixic acid and ciprofloxacin-resistant E. coli was also high.

In our study, a high percentage of $E$. coli were harbored multiple ARGs. The most frequent resistance genes were bla TEM followed by sul1, tetA, and sul2. bla $a_{T E M}$ is the prevalent ARGs among clinical E. coli strains [25]. Our data showed that tet $A$ was the most frequently detected resistant determinant among tetracycline-resistant isolates. The prevalence of bla $a_{C T X-M}$ harboring $E$. coli was low in the current study. The prevalence of bla $a_{S H V}$ was higher than those previously reported by many studies $[25,26]$. In sulfonamide-resistant E. coli, sul1 was predominant. Aminoglycosides resistant determinant, strA, aphA2 were frequent among streptomycin-resistant and gentamicin-resistant isolates respectively. Our results showed that dhfr1, dhfr 7 , and cat 1 genes were detected less frequently. Similar to our study, several studies reported the presence of PMQR genes among clinical $E$. coli isolates $[25,26]$.

The virulence genes iutA, kpsMT II, sfa/focDE, and papAH showed an association with ARGs. Whereas adhesion-related gene, papC did not show a positive association with any of the ARGs. iutA and papAH showed an association with trimethoprim resistance genes (dfhr). sfa/focDE and iutA showed a negative association with some of the ARGs. The prevalence of bla $a_{T E M}, t e t B$, and cat 1 genes was high among sfa/focDE negative isolates. The prevalence of ESBL gene, bla CTXM $_{\text {was }}$ wigh in iut $A$ negative isolates, which is in contrast to the findings of Chakraborty et al. [22]. papAH was the virulent gene that showed association with multiple ARGs $(n=8)$.

Apart from cat1 gene, all the tested ARGs showed a significant positive association with int1 among $E$. coli isolates. Int1 was more prevalent in sfa/focDE negative isolates, whereas papAH and kpsMT II correlates with a high incidence of int1. Integrons are genetic elements able to integrate and express diverse open reading frames included in gene cassettes. Integrons carry antibiotic resistance genes, being frequently associated with multidrug resistance in Gram-negative bacteria.

\section{Conclusion}

The present study revealed a significant association between the presence of virulence genes and antibiotic resistance. The high prevalence of multidrug-resistant $E$. coli is of great concern; it may result in treatment failure and reducing therapeutic choices. Understanding the association between extraintestinal virulence genes and antibiotic resistance genes would result in the proper treatment of urinary tract infections.

\section{ACKNOWLEDGMENTS}

Dr. Divya would like to thank the Council of Scientific and Industrial Research (CSIR), Govt of India for the research fellowship to carry out the work. The authors are also thankful to the Head, Department of Marine Biology, Microbiology and Biochemistry, Cochin University of Science and Technology for providing the facilities.

Declaration of Conflicting Interests: The authors declare that they have no conflict of interest.

Funding: Not applicable.

\section{REFERENCES}

1. WHO. Critically important antimicrobials for human medicine 5th revision. World Health Organization, Geneva, Switzerland. http://who.int/foodsafety/ publications/antimicrobialsfifth/en/. 2017. (accessed 21.06.20).

2. Ewers $\mathrm{C}$, Li G, Wilking $\mathrm{H}$, Kiessling $\mathrm{S}$, et al. Avian pathogenic, uropathogenic, and newborn meningitiscausing Escherichia coli: How closely related are they? Int J Med Microbiol 2007;297: 163-176. 
3. Barrow GI, Feltham RKA. Cowan and Steel's manual for the identification of medical bacteria.1993:317

4. Bej AK, Dicesare JL, Haff L, et al. Detection of Escherichia coli and Shigella spp. in water by using the polymerase chain reaction and gene probes for uid. Appl Environ Microbiol 1991;57: 1013-1017.

5. Sambrook J, Fritsch E, Maniatis V. Molecular Cloning. A Laboratory Manual. New York: Cold spring Harbor Laboratory Press.1989.

6. Clermont O, Christenson JK, Denamur E, et al. The Clermont Escherichia coli phylo-typing method revisited: Improvement of specificity and detection of new phylo-groups. Environ Microbiol Rep 2013;5: 5865.

7. Johnson JR, Stell AL. Extended virulence genotypes of Escherichia coli strains from patients with urosepsis in relation to phylogeny and host compromise. J Infect Dis 2000; 181:261-272.

8. Bauer AW, Kirby WMM, Skerris JC, et al. Antibiotic susceptibility testing by a standardized single diffusion method. Am J Clin Pathol 1966;454: 493-496.

9. CLSI. Clinical and Laboratory Standard Institute. Performance Standards for Antimicrobial Susceptibility Testing; Twenty-Second Informational Supplement. CLSI Document M100-S22, Clinical and Laboratory Standard Institute, Wayne, 2012.

10. Krumperman $\mathrm{PH}$. Multiple Antibiotic resistance indexing of Escherichia coli to identify high-risk sources of fecal contamination of foods. Appl Environ Microbiol 1983; 46:165-170.

11. Maynard C, Fairbrother JM, Bekal S, et al. Antimicrobial resistance genes in enterotoxigenic Escherichia coli 0149:K91 isolates obtained over a 23-year period from pigs. Antimicrob Agents Chemother 2003; 47:3214-3221.

12. Dallenne C, da Costa A, Decré $D$, et al. Development of a set of multiplex PCR assays for the detection of genes encoding important $\beta$-lactamases in Enterobacteriaceae. J Antimicrob Chemother 2010; 65:490-495.

13. Batchelor M, Hopkins K, Threlfall EJ, et al. bla $M$ genes in clinical Salmonella isolates recovered from humans in england and wales from 1992 to 2003. Antimicrob Agents Chemother 2005; 49:1319-1322.

14. Rosengren LB, Waldner CL, Reid-Smith RJ. Associations between antimicrobial resistance phenotypes, antimicrobial resistance genes, and virulence genes of fecal Escherichia coli isolates from healthy grow-finish pigs. Appl Environ Microbiol 2009; 75:1373-1380.

15. Navia MM, Ruiz J, Sanchez-Cespedes J, et al. Detection of dihydrofolate reductase genes by PCR and RFLP. Diagn Microbiol Infect Dis 2003; 46:295298.
16. Cattoir V, Poirel L, Rotimi V, et al. Multiplex PCR for detection of plasmid-mediated quinolone resistance qnr genes in ESBL-producing enterobacterial isolates. J Antimicrob Chemother 2007; 60:394-397.

17. Benaicha H, Barrijal S, Ezzakkioui $F$, et al. Prevalence of PMQR genes in E. coli and Klebsiella spp. isolated from North-West of Morocco. J Glob Antimicrob Resist 2017; 10:321-325.

18. Kim KY, Park JH, Kwak HS, et al. Characterization of the quinolone resistance mechanism in foodborne Salmonella isolates with high nalidixic acid resistance. Int J Food Microbiol 2011; 146:52-56.

19. Kraft CA, Timbury MC, Platt DJ. Distribution and genetic location of $\mathrm{Tn} 7$ in trimethoprim-resistant Escherichia coli. J Med Microbiol 1986; 22:125-131.

20. Goldstein C, Lee MD, Sanchez S, et al. Incidence of class 1 and 2 integrases in clinical and commensal bacteria from livestock, companion animals, and exotics. Antimicrob Agents Chemother 2001; 45:723726.

21. Meacham KJ, Zhang L, Foxman B, et al. Evaluation of genotyping large numbers of Escherichia coli isolates by enterobacterial repetitive intergenic consensus-PCR. J Clin Microbiol 2003; 41:5224-5226.

http://jcm.asm.org/content/41/11/5224.full.

22. Chakraborty A, Adhikari P, Shenoy $S$, et al. Molecular characterization and clinical significance of extraintestinal pathogenic Escherichia coli recovered from a south Indian tertiary care hospital. Microb Pathog 2016; 95:43-48.

23. Johnson JR, Russo TA. Molecular epidemiology of extraintestinal pathogenic (uropathogenic) Escherichia coli. Int J Med Microbiol 2005; 295:383404.

24. van Hoek AHAM, Stalenhoef JE, van Duijkeren E, et al. Comparative virulotyping of extended-spectrum cephalosporin-resistant $E$. coli isolated from broilers, humans on broiler farms and in the general population and UTI patients. Vet Microbiol 2016; 194:55-61.

25. Shahbazi S, Asadi KMR, Habibi M, et al. Distribution of extended-spectrum $\beta$-lactam, quinolone and carbapenem resistance genes, and genetic diversity among uropathogenic Escherichia coli isolates in Tehran, Iran. J Glob Antimicrob Resist 2018; 14:118-125.

26. Al-Agamy $\mathrm{MH}$, Aljallal $\mathrm{A}$, Radwan $\mathrm{HH}$, et al. Characterization of carbapenemases, ESBLs, and plasmid-mediated quinolone determinants in carbapenem-insensitive Escherichia coli and Klebsiella pneumoniae in Riyadh hospitals. J Infect Public Health 2018; 11:64-68. 